\title{
Diffuse Alopecia Areata Revealing Euthyroid Hashimoto Thyroiditis
}

\author{
Salem Bouomrani ${ }^{1,2 *}$ Wided Letaief ${ }^{2,3}$, Ines Lamloum ${ }^{1,2}$, Khawla Souid $^{1,4}$, Ali Naffati ${ }^{1,2}$, Amin \\ Hammami $^{1,2}$, Warda Mahdhaoui ${ }^{1,2}$ \\ ${ }^{1}$ Department of Internal medicine, Military Hospital of Gabes, Gabes Tunisia \\ ${ }^{2}$ Sfax Faculty of Medicine, University of Sfax, Sfax, Tunisia \\ ${ }^{3}$ Department of Obstetrics and Gynecology, Regional Hospital of Gabes, Gabes , Tunisia \\ ${ }^{4}$ Dermatology consultant. Derma-Sud center, Street, Gabes, Tunisia
}

*Corresponding Author: Salem Bouomrani1, Department of Internal medicine, Military Hospital of Gabes, Gabes, Faculty of Medicine, University of Sfax, Sfax, Tunisia, Email: salembouomrani@yahoo.fr

\begin{abstract}
Thyroid dysfunction can be noted in up to $24 \%$ of cases of alopecia areata. The positivity of antithyroid autoantibodies, subclinical hypothyroidism, and overt hypothyroidism or hyperthyroidism are the most frequent thyroid dysfunction associated to alopecia areata. Euthyroid autoimmune thyroiditis remains an exceptional cause of new onset alopecia.

We report an original observation of diffuse non-cicatricialalopecia areata revealing euthyroid Hashimoto thyroiditis in 30-year-old Tunisian woman withfavorable course under low dose of hormone replacement therapy.
\end{abstract}

Keywords: Alopecia areata, Hashimoto thyroidites, Thyroid dysfunction, Alopecia.

\section{INTRODUCTION}

Abnormal thyroid function and the positivity of antithyroid autoantibodies can be noted in up to $24 \%$ of cases of alopecia areata [1]. The overt/symptomatic forms of thyroid dysfunction (hypothyroidism or hyperthyroidism) are the most frequent [2].

Described first in 1912 by the Japanese physician Hashimoto Hakaru, Hashimoto's thyroiditis (HT) is the most common thyroiditis [3] and the most common autoimmune disease [4]. The clinical presentations of this thyropathy are very polymorphic and sometimes non-specific [5-7], making its diagnosis a real challenge, especially in primary care $[3,5]$. We report an original observation of diffuse alopecia areata revealing euthyroidHT.

\section{CASE REPORT}

30-year-old Tunisian woman, with no notable pathological historywas referred by her family doctor for exploration of a diffuse alopecia areataworsening progressively over the past four months.

The somatic examination was without abnormalities apart from diffuse alopecia areata at the frontal, occipital, and parieto-temporal areas (Figures 1, 2, 3, and 4).

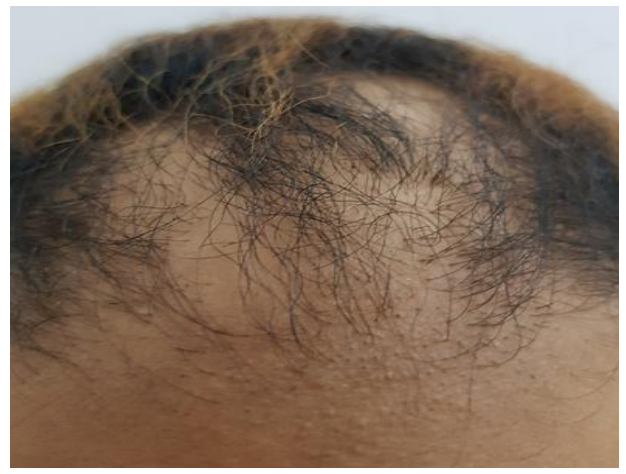

Fig1: Frontal alopecia (anterior view).

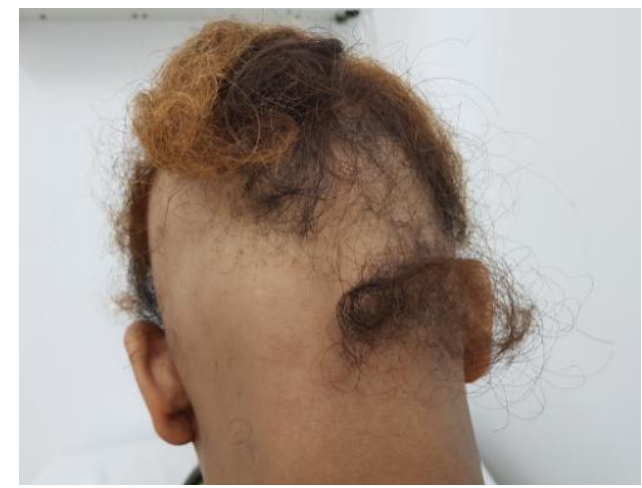

Fig2: Parieto-occipital alopecia (posterior view).

Page 9 


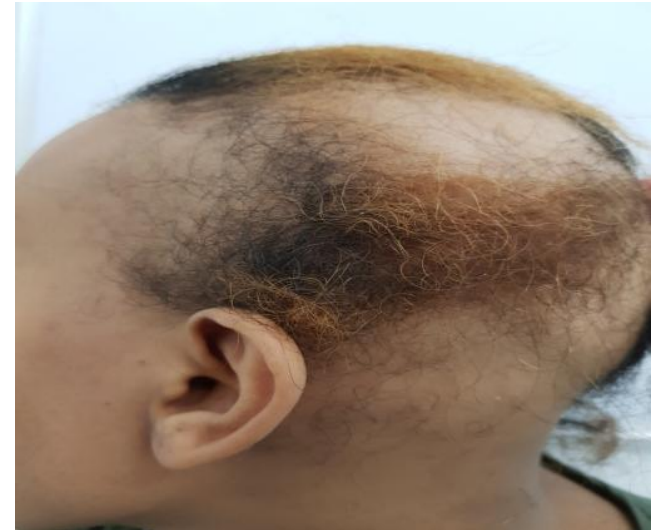

Fig3: Left pareto-temporal alopecia (left profile view).

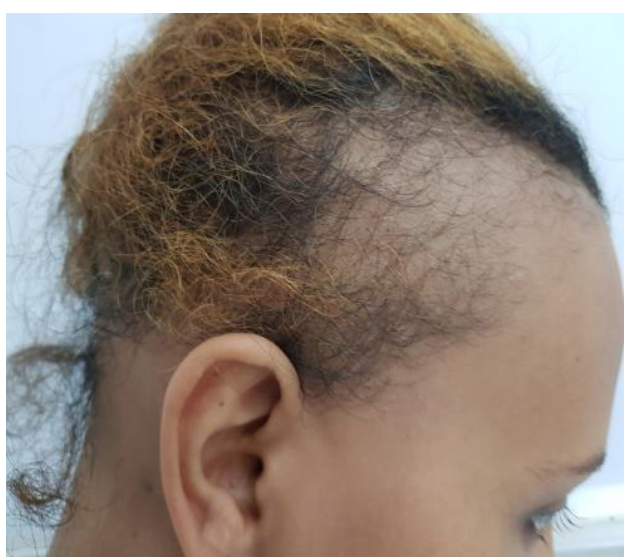

Fig4: Right parieto-temporal alopecia (right profile view).

The basic biology was without significant anomalies (hemoglobin, leukocytes, platelets, erythrocyte sedimentation rate, C-reactive protein, creatinine, calcemia, ionogram, transaminases, muscle enzymes, lipid parameters, and electrophoresis of plasma proteins). Thyroid tests were also normal: thyroid stimulating hormone (TSH) at $1.92 \mu \mathrm{IU} / \mathrm{ml}$ and total free thyroxin (FT4) at $11.45 \mathrm{pmol} / 1$.

Skin biopsy showed nonspecific non-cicatricial alopecia.

Immunological tests objectified negative antinuclear autoantibodies; negative anti-double stranded DNA antibodies, positiveanti-thyroid peroxidase (anti-TPO) antibodies at 118.6IU, and positiveanti-thyroglobulin antibodies at 120IU. The cervical ultrasound showed a heterogeneous and micronodularmoderate goiter compatible with the diagnosis of thyroiditis.

The rest of the etiological explorations were without anomalies.

The diagnosis of HT in the euthyroid phase was retained. A low dose of thyroxine $(25 \mu \mathrm{g} /$ day $)$ was prescribed with a favorable course.
Progressive regrowth of hair was noted from the second week of treatment (Figures 5, 6, and 7).

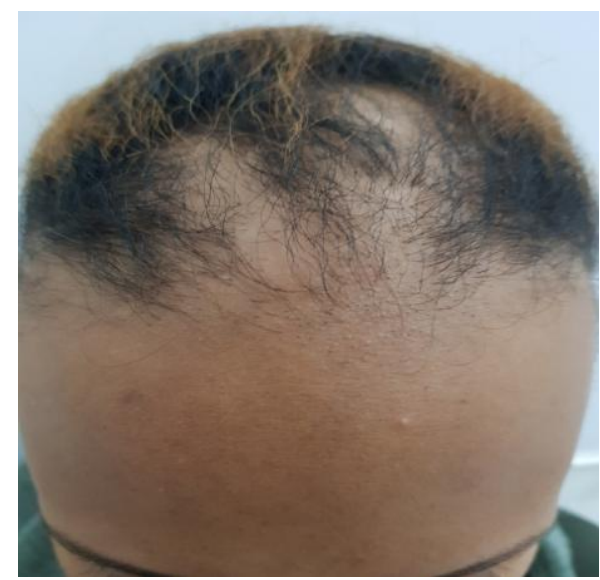

Fig5: Improvement of frontal alopecia after two weeks of hormone replacement therapy.

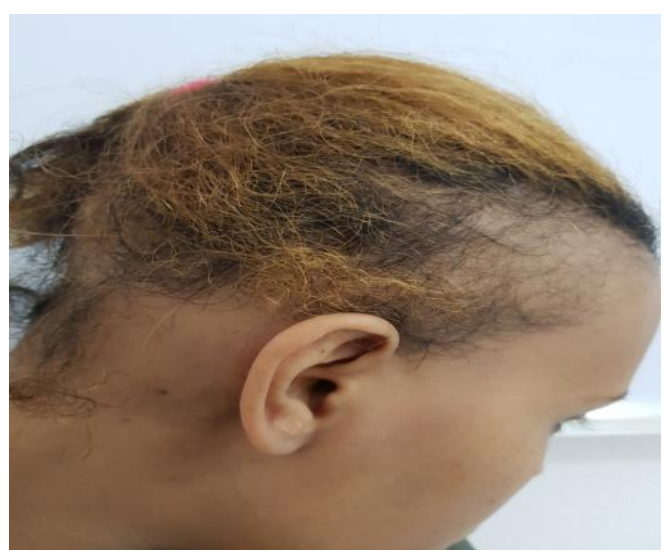

Fig.6: Improvement of right parieto-temporal alopecia after two weeks of hormone replacement therapy

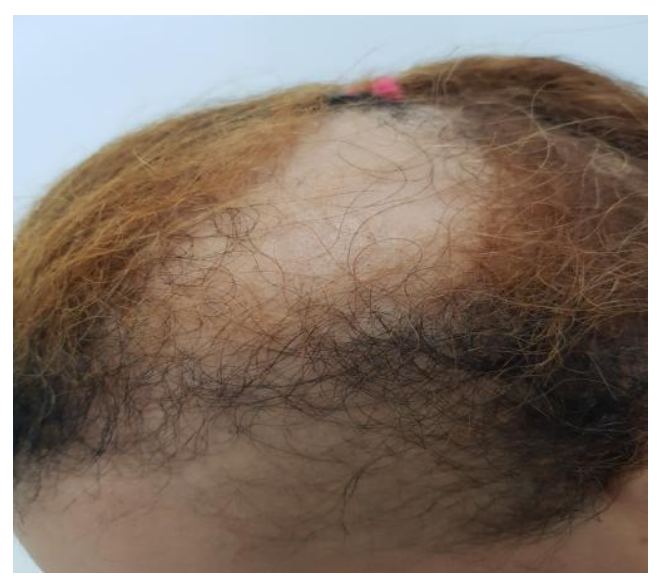

Fig7: Improvement of left parieto-temporal alopecia after two weeks of hormone replacement therapy.

\section{DISCUSSION}

Alopecia can be a revealing sign of deep hypothyroidism or hyperthyroidism $[8,9]$ due to the crucial role of thyroid hormones in hair formation and growth through increased oxygenation of the epidermis, protein synthesis, and mitosis control $[8,10]$. 
It seems to be particularly associated with autoimmune thyroiditis [11-13] and is usually reversible after hormone replacement therapy normalizing TSH [8-13].

Different types of alopecia have been reported during dysthyroidism: diffuse alopecia, alopecia areata, androgenetic alopecia, alopecia totalis, alopecia universalis, cicatricial alopecia, madarosis, diminished/absent facial hair, and diminished body hair $[9,12]$.

Diffuse alopecia andalopecia areataare the main types in in patients with thyroid dysfunction [9, 12].

Alopecia can be associated to positive antithyroid auto-antibodies, subclinical hypothyroidism, and overt hypothyroidism or hyperthyroidism [1, 9, and 12].

Euthyroid autoimmune thyroiditis remains an exceptional cause of alopecia: only four patients $(5 \%)$ in Lyakhovitsky A et al series of 78 patients with new onset alopecia areata [1].

\section{CONCLUSION}

As rare as it is, this exceptional clinical presentation of euthyroid Hashimoto's thyroiditis deserves to be known by healthcare professionals.

A screening and a periodic control of the thyroid function (thyroid hormonesand anti-thyroid autoantibodies) are thus recommended in front of any alopecia that is not proven.

\section{REFERENCES}

[1] Lyakhovitsky A, Shemer A, Amichai B. Increased prevalence of thyroid disorders in patients with new onset alopecia areata. Australas J Dermatol. 2015; 56(2):103-6.

[2] Thomas EA, Kadyan RS. Alopecia areata and autoimmunity: a clinical study. Indian J Dermatol. 2008; 53(2):70-4.
[3] Baretić M. 100 years of Hashimoto thyroiditis, still an intriguing disease. Acta Med Croatica. 2011; 65(5):453-7.

[4] Caturegli P, De Remigis A, Rose NR. Hashimoto thyroiditis: clinical and diagnostic criteria. Autoimmun Rev. 2014; 13(4-5):391-7.

[5] Bouomrani S, Guermazi M, Yahyaoui S, Nouma H. Acute Hepatitis-Like Syndrome Revealing Hashimoto Thyroiditis. Sci J Gastroenterol \& Hepatol. 2018; 1(2):1-3.

[6] Bouomrani S, Rgaïeg N. Isolated nonautoimmune neutropenia revealing primary Hypothyroidism. Blood Heart Circ. 2019; 3:1-3.

[7] Bouomrani S, Regaieg N, Belgacem N, Ben Hamed M, Lassoued N, Trabelsi S, et al. Myositis-Like Syndrome Revealing Hypothyroidism. Archives of Diabetes and Endocrine System. 2018;1(2):1-3.

[8] Ishak F, Badri T, Benmously R, Mokhtar I, Fenniche S. Diffuse alopecia.Rev Med Interne. 2011; 32(6):377-8.

[9] Vincent M, Yogiraj K.A Descriptive Study of Alopecia Patterns and their Relation to Thyroid Dysfunction. Int J Trichology. 2013; 5(1):57-6 0.

[10] Contreras-Jurado C, García-Serrano L, Martínez-Fernández M, Ruiz-Llorente L, Paramio JM, Aranda A.Impaired hair growth and wound healing in mice lacking thyroid hormone receptors. PLoS One. 2014; 9(9):e108137.

[11] Kurtev A, Iliev E. Thyroid autoimmunity in children and adolescents with alopecia areata.Int J Dermatol. 2005; 44(6):457-61.

[12] Park SM, Oh YJ, Lew BL, Sim WY. he association among thyroid dysfunction, thyroid autoimmunity, and clinical features of alopecia areata: A retrospective study.J Am Acad Dermatol. 2019; 81(2):602-605.

[13] Baars MP, Greebe RJ, Pop VJ.High prevalence of thyroid peroxidase antibodies in patients with alopecia areata.J EurAcad Dermatol Venereol. 2013; 27(1):e137-9.

Citation: Salem Bouomrani, Wided Letaief, et.al. Diffuse Alopecia Areata Revealing Euthyroid Hashimoto Thyroiditis ARC Journal of Diabetes and Endocrinology. 2019; 5(2):9-11. doi:dx.doi.org/10.20431/2455-5983. 0502002.

Copyright:(C) 2019 Authors. This is an open-access article distributed under the terms of the Creative Commons Attribution License, which permits unrestricted use, distribution, and reproduction in any medium, provided the original author and source are credited. 